\title{
META-ANALYSIS OF SYSTEMIC ANTI-FIBRINOLYTICS IN TRAUMATIC HYPHAEMA
}

\author{
G. W. AYLWARD ${ }^{1}$, I. S. DUNLOP ${ }^{2}$ and B. C. LITTLE ${ }^{1}$ \\ London and Sydney, Australia
}

\begin{abstract}
SUMMARY
We report a meta-analysis of randomised, controlled, clinical trials of systemic anti-fibrinolytics in traumatic hyphaema. Outcome measures were rate of secondary haemorrhage and final visual acuity. An estimate of the overall odds ratio for each outcome measure was calculated both by combining the logarithms of the odds ratios, and by the Mantel-Haenszel method. The results confirm a beneficial effect of systemic antifibrinolytics on the rate of secondary haemorrhage, but not on final visual acuity.
\end{abstract}

Traumatic hyphaema is a relatively common problem in ophthalmic primary care, accounting for about one patient per week in a recent survey of an ophthalmic accident and emergency department. ' In a minority of cases secondary haemorrhage occurs and this may be associated with serious complications. ${ }^{2}$ Several management strategies have been advocated in the literature, the common aim of which has been to reduce the chance of secondary haemorrhage. Anti-fibrinolytic agents have been employed for this purpose, and several studies have indicated that their use is associated with a decreased risk of secondary haemorrhage. ${ }^{3}$ In the United Kingdom, however, anti-fibrinolytics are seldom prescribed for traumatic hyphaema. In a recent survey of consultant ophthalmologists, only $2 \%$ of respondents would consider using anti-fibrinolytic agents. ${ }^{4}$ Support for this view comes from recent retrospective studies which indicate that secondary haemorrhage is not necessarily associated with a poor visual outcome..$^{5-7}$

Meta-analysis is a method of formal statistical analysis of data from several published trials, and may be considered to be a more rigorous alternative to narrative literature review. It has been widely applied in the social sciences, psychology and medicine, for example to resolve doubts about the role of intravenous streptokinase

From: 'Moorfields Eye Hospital, London, UK; ${ }^{2}$ Sydney Eye Hospital, Sydney, Australia.

Correspondence to: Mr G. W. Aylward, FRCS, FRCOphth, MD, Moorfields Eye Hospital, City Road, London ECIV 2PD, UK. in the management of acute myocardial infarction. ${ }^{8}$ The use of anti-fibrinolytics in the management of traumatic hyphaema has been the subject of several well-conducted, randomised, controlled clinical trials. ${ }^{9-14}$ However, the results of these trials are not in agreement, four finding a beneficial effect of anti-fibrinolytics and two failing to find an effect. This is the type of controversy that metaanalysis can help to resolve.

We carried out a meta-analysis of published trials of anti-fibrinolytic agents in order to answer two questions concerning the effect of systemic antifibrinolytic agents in traumatic hyphaema: (1) Is there a reduction in the rate of secondary haemorrhage? (2) Is there an effect on final visual outcome?

\section{METHODS}

Published trials of anti-fibrinolytic agents in the treatment of traumatic hyphaema were located by searching biomedical computer databases, recent review articles and reference lists of relevant reports. Only those trials which used a prospective, randomised, controlled study design were included in the analysis. Six such publications were found, in four of which the anti-fibrinolytic agent was aminocaproic acid ${ }^{9-12}$ and in two of which it was tranexamic acid. ${ }^{13,14}$

The following data were extracted from each trial report: The number of patients in both treatment and control groups with (1) secondary haemorrhage, (2) final visual acuity of $6 / 18$ or worse, and (3) final visual acuity of $6 / 60$ or worse. Figures for secondary haemorrhage were available in all six reports, but data on visual acuity were not given in one report. ${ }^{13}$

We carried out meta-analysis for the three separate sets of data described by constructing standard $2 \times 2$ tables, with columns for treated patients and controls, and rows for presence or absence of the outcome. Where zero entries were present for both treated and control groups (for example the rate of secondary haemorrhage in the study of Vangsted and Nielsen ${ }^{14}$ ), that $2 \times 2$ table was 
excluded from analysis for that outcome. An estimate of the overall odds ratio $(\hat{o})$ was calculated in two different ways: firstly by combining the logarithms of the odds ratios for each study in a weighted average according to the method described by Fleiss, ${ }^{15}$ and secondly by calculating the Mantel-Haenszel summary estimate of the odds ratio $\left(\hat{o}_{\mathrm{MH}}\right){ }^{16}$

Heterogeneity of the data was tested for by calculating the overall $\chi^{2}$ for homogeneity and referring it to the $\chi^{2}$ distribution with $(n-1)$ degrees of freedom, where $n$ is the number of studies combined. ${ }^{17}$ An estimate of the standard error of the logarithm of the common odds ratio was used to construct $95 \%$ confidence intervals. ${ }^{15}$ In the case of $\hat{o}_{\mathrm{MH}}$, the estimate of the variance suggested by Robins $e t$ $a l .{ }^{18}$ was used to construct $95 \%$ confidence intervals. This was applied on a logarithmic scale due to the skewness of the distribution of $\hat{o}_{\mathrm{MH}}$. The appropriate $\chi^{2}$ statistics were also calculated for each estimate and referred to tables of the $\chi^{2}$ distribution with one degree of freedom. The validity of doing so was confirmed using the rule for minimum expected cell size requirements developed for $\hat{o}_{\mathrm{MH}}$ by Mantel and Fleiss. ${ }^{19}$

\section{RESULTS}

Tables I to III give the raw data used in the $2 \times 2$ tables for the three outcome measures: rate of secondary haemorrhage, final visual acuity $6 / 18$ or worse, and final visual acuity $6 / 60$ or worse.

The studies used in each meta-analysis and the results

Table I. Figures for secondary haemorrhage

\begin{tabular}{|c|c|c|c|c|}
\hline \multirow[b]{2}{*}{ Study } & \multicolumn{2}{|c|}{ Control group } & \multicolumn{2}{|c|}{ Treated group } \\
\hline & Yes & No & Yes & No \\
\hline 1. Crouch and Frenkel ${ }^{9}$ & 9 & 18 & 1 & 31 \\
\hline 2. McGetrick et al. ${ }^{10}$ & 7 & 14 & 1 & 27 \\
\hline 3. Kutner et al. ${ }^{.1}$ & 3 & 10 & 0 & 21 \\
\hline 4. Kraft et al. ${ }^{12}$ & 1 & 24 & 2 & 22 \\
\hline 5. Varnek et al. ${ }^{13}$ & 12 & 118 & 2 & 100 \\
\hline 6. Vangsted and Nielsen ${ }^{14}$ & 0 & 53 & 0 & 59 \\
\hline
\end{tabular}

Table III. Figures for final visual acuity of $6 / 60$ or worse

\begin{tabular}{|c|c|c|c|c|}
\hline \multirow[b]{2}{*}{ Study } & \multicolumn{2}{|c|}{ Control group } & \multicolumn{2}{|c|}{ Treated group } \\
\hline & Yes & No & Yes & No \\
\hline 1. Crouch and Frenkel ${ }^{y}$ & 6 & 21 & 4 & 28 \\
\hline 2. McGetrick et al. ${ }^{10}$ & 4 & 17 & 5 & 23 \\
\hline 3. Kutner et al. ${ }^{11}$ & 1 & 12 & 2 & 19 \\
\hline 4. Kraft et al. ${ }^{12}$ & 0 & 25 & 0 & 24 \\
\hline 5. Varnek et al. ${ }^{13}$ & - & - & - & - \\
\hline 6. Vangsted and Nielsen ${ }^{14}$ & 0 & 53 & 0 & 59 \\
\hline
\end{tabular}

Table V. Results of meta-analysis using combined logarithms of odds ratios

\begin{tabular}{lcrccc}
\hline Outcome measure & $\hat{o}$ & \multicolumn{1}{c}{$\chi^{2}$} & \multicolumn{1}{c}{$p$} & $\begin{array}{c}\text { 95\% confidence } \\
\text { interval for } \hat{o}\end{array}$ \\
\hline Secondary haemorrhage & 4.82 & 13.73 & $<0.001$ & 2.10 to 11.06 \\
Final VA 6/18 or worse & 1.41 & 1.32 & 0.25 & 0.78 to 2.51 \\
Final VA 6/60 or worse & 1.36 & 0.48 & 0.49 & 0.57 to 3.27 \\
\hline
\end{tabular}

of the tests for heterogeneity are shown in Table IV. It can be seen that there is no significant divergence between the results of the various studies, thus satisfying a fundamental condition necessary for calculating any overall summary statistic. ${ }^{17}$

The estimates for the overall odds ratios for the three outcome measures, along with $95 \%$ confidence limits, are shown in Tables V and VI. There is broad agreement between the results from both methods. Both $\hat{o}$ and $\hat{o}_{\mathrm{MH}}$ for secondary haemorrhage are significantly greater than unity, confirming a greater risk of secondary haemorrhage in the untreated patients. For final visual acuity, neither estimate supports a difference between treated and untreated patients.

\section{DISCUSSION}

The results of our meta-analysis confirm that systemic anti-fibrinolytics reduce the rate of secondary haemorrhage in patients with traumatic hyphaema. A treatment effect was found by four of the published trials used in the meta-analysis, ${ }^{9-11.13}$ the remaining two finding no difference between the treated and untreated group. ${ }^{12.14}$ This illustrates the power of meta-analysis to resolve controversy in a scientific manner. The visual benefit of a reduction in the rate of secondary haemorrhage, however, is not clear from this study. No significant difference in final visual outcome could be detected between the treatment and control groups, suggesting that a secondary haemorrhage, as defined in the published trials, is not necessarily

Table II. Figures for final visual acuity of $6 / 18$ or worse

\begin{tabular}{|c|c|c|c|c|}
\hline \multirow[b]{2}{*}{ Study } & \multicolumn{2}{|c|}{ Control group } & \multicolumn{2}{|c|}{ Treated group } \\
\hline & Yes & No & Yes & No \\
\hline 1. Crouch and Frenkel ${ }^{9}$ & 9 & 18 & 7 & 25 \\
\hline 2. McGetrick et al. ${ }^{10}$ & 7 & 14 & 6 & 22 \\
\hline 3. Kutner et al. ${ }^{11}$ & 3 & 10 & 7 & 14 \\
\hline 4. Kraft et al. ${ }^{12}$ & 5 & 20 & 7 & 17 \\
\hline 5. Varnek et al. ${ }^{13}$ & - & - & - & - \\
\hline 6. Vangsted and Nielsen ${ }^{14}$ & 8 & 45 & 2 & 57 \\
\hline
\end{tabular}

Table IV. Figures for $\chi^{2}$ for homogeneity of the data from the component studies

\begin{tabular}{lcccc}
\hline Outcome measure & $\begin{array}{c}\text { Studies } \\
\text { combined }\end{array}$ & $\chi_{\text {HомОG }}^{2}$ & $\begin{array}{c}\text { Degrees of } \\
\text { freedom }\end{array}$ & $p$ \\
\hline Secondary haemorrhage & $1-5$ & 5.87 & 4 & 0.21 \\
Final VA 6/18 or worse & $1-4,6$ & 5.13 & 4 & 0.27 \\
Final VA 6/60 or worse & $1-3$ & 0.46 & 2 & 0.79 \\
\hline
\end{tabular}

VA, visual acuity.

"See Tables I-III.

Table VI. Results of meta-analysis using Mantel-Haenszel estimate

\begin{tabular}{lccccc}
\hline Outcome measure & $\hat{o}_{\mathrm{MH}}$ & $\chi_{\mathrm{MH}}^{2}$ & $p$ & $\begin{array}{r}\text { 95\% confidence } \\
\text { interval for } \hat{o}_{\mathrm{MH}}\end{array}$ \\
\hline Secondary haemorrhage & 6.21 & 20.01 & $<0.001$ & 2.57 to 14.96 \\
Final VA 6/18 or worse & 1.46 & 1.32 & 0.25 & 0.82 to 2.60 \\
Final VA 6/60 or worse & 1.36 & 0.18 & 0.67 & 0.55 to 3.42 \\
\hline
\end{tabular}


as devastating an event as has previously been supposed. Recent large and detailed retrospective studies have shown that poor visual acuity is usually attributable to retinal pathology, rather than any sequelae of rebleeding. ${ }^{5,6}$

Meta-analysis has been criticised as a method of reviewing the literature because it combines data from trials with different patient characteristics and study designs. The trials used in the present meta-analysis had very similar design, although the patient groups did vary in age and ethnic origin. For example, the study of Kraft $e t$ $a l{ }^{12}$ was conducted in a children's hospital, and no patients older than 18 years were included. The presence of such differences is inevitable, but may also be interpreted as an advantage, since it allows wider generalisation of the results than any of the individual trials alone. ${ }^{20}$ A more serious criticism is that meta-analysis, based as it is on all published trials, is prone to publication bias. There is evidence that a trial with a significant treatment effect is more likely to be published in a medical journal than one with non-significant results. ${ }^{21}$

The clinical decision of whether to use anti-fibrinolytics in the management of traumatic hyphaema is a multifactorial one. The severity of the hyphaema, the age and condition of the patient, the possible side-effects and the cost of treatment all contribute to the decision, as well as the likelihood of a beneficial treatment effect. Our metaanalysis suggests that although anti-fibrinolytics will reduce the chance of a secondary haemorrhage occurring, the benefit of doing so is unclear.

Key words: Aminocaproic acid, Hyphaema, Meta-analysis, Secondary haemorrhage, Tranexamic acid, Trauma.

\section{REFERENCES}

1. Jones NP, Hayward JM, Khaw PT, Claoué CMP, Elkington AR. Function of an ophthalmic 'accident and emergency' department: results of a six month survey. BMJ 1986;292: 188-90.

2. Thygeson P, Beard C. Observations on traumatic hyphema. Am J Ophthalmol 1952;35:977-85.

3. Read J, Goldberg MF. Comparison of medical treatment for traumatic hyphema. Tr Am Acad Ophthalmol Otolaryngol 1974;78:799-815.

4. Little BC, Aylward GW. The medical management of acute hyphaema: a survey of opinion among ophthalmologists in the United Kingdom. J R Soc Med 1993;86:458-9.
5. Kearns P. Traumatic hyphaema: a retrospective study of 314 cases. Br J Ophthalmol 1991;75:137-41.

6. Ng CS, Sparrow JM, Strong NP, Rosenthal AR. Factors related to the final visual outcome of 425 patients with traumatic hyphaema. Eye 1992;6:305-7.

7. Volpe NJ, Larrison WI, Hersch PS, Kim T, Shingleton BJ. Secondary haemorrhage in traumatic hyphaema. Am J Ophthalmol 1991;112:507-13.

8. Stampfer MJ, Goldhaber SZ, Yusuf S, Peto R, Hennekens $\mathrm{CH}$. Effect of intravenous streptokinase on acute myocardial infarction: pooled results from randomised trials. $\mathrm{N}$ Engl $\mathbf{J}$ Med 1982;307:1180-2.

9. Crouch ER, Frenkel M. Aminocaproic acid in the treatment of traumatic hyphema. Am J Ophthalmol 1976;81:355-60.

10. McGetrick JJ, Jampol LM, Goldberg MF, Frenkel M, Fiscella RG. Aminocaproic acid decreases secondary hemorrhage after traumatic hyphema. Arch Ophthalmol 1983;101:1031-3.

11. Kutner B, Fourman S, Brein K, Hobson S, Mrvos D, Sheppard J, Weisman S. Aminocaproic acid reduces the risk of secondary haemorrhage in patients with traumatic hyphema. Arch Ophthalmol 1987;105:206-8.

12. Kraft SP, Christianson MD, Crawford JS, Wagman RD, Antoszyk JH. Traumatic hyphaema in children: treatment with epsilon-aminocaproic acid. Ophthalmology 1987;94: 1232-7.

13. Varnek L, Dalsgaard C, Hansen A, Klie F. The effect of tranexamic acid on secondary haemorrhage after traumatic hyphaema. Acta Ophthalmol (Copenh) 1980;58:787-93.

14. Vangsted P, Nielsen PJ. Tranexamic acid and traumatic hyphaema: a prospective study. Acta Ophthalmol (Copenh) 1983;61:447-53.

15. Fleiss JL. Statistical methods for rates and proportions, 2nd ed. New York: Wiley, 1981:165.

16. Mantel N, Haenszel W. Statistical aspects of the analysis of data from retrospective studies of disease. J Nat Can Inst 1959;22:719-48.

17. Breslow NE, Day NE. Statistical methods in cancer research, vol. II. New York: Oxford University Press, 1987: 110.

18. Robins J, Breslow N, Greenland S. Estimators of the Mantel-Haenszel variance consistent in both sparse data sets and large-strata limiting models. Biometrics 1986;42:311-23.

19. Mantel N, Fleiss JL. Minimum expected cell size requirements for the Mantel-Haenszel one-degree-of-freedom chisquare test and a related rapid procedure. Am J Epidemiol 1980;112:129-34.

20. Elwood PC. Randomised controlled trials: sampling. $\mathrm{Br} \mathbf{J}$ Clin Pharmacol 1982;13:631-6.

21. Begg CB, Berlin JA. Publication bias: a problem in interpreting medical data. J R Statist Soc 1988;151:419-63. 